\section{Orf in the Country}

SIR,-The series of cases of orf occurring among Smithfield porters, described by Dr. I. S. Hodgson-Jones (April 14, p. 795) shows some clinical variations from those occurring in a rural area among agricultural workers. This is probably accounted for by their outdoor employment. Nine cases have been recorded by me since the war years, when time did not allow for aciequate observation of earlier cases.

In no case has the dead, white, soggy skin been seen except where marked secondary infection has supervened. Lymphangiitis has not been detected until the vesicle has been broken, so that one has come to regard it as associated with secondary infection. Generally, a single lesion is seen, but cases have occurred where the primary lesion has remained small and a circinate group of secondary lesions have broken down, simulating the classical illustration in the older text-

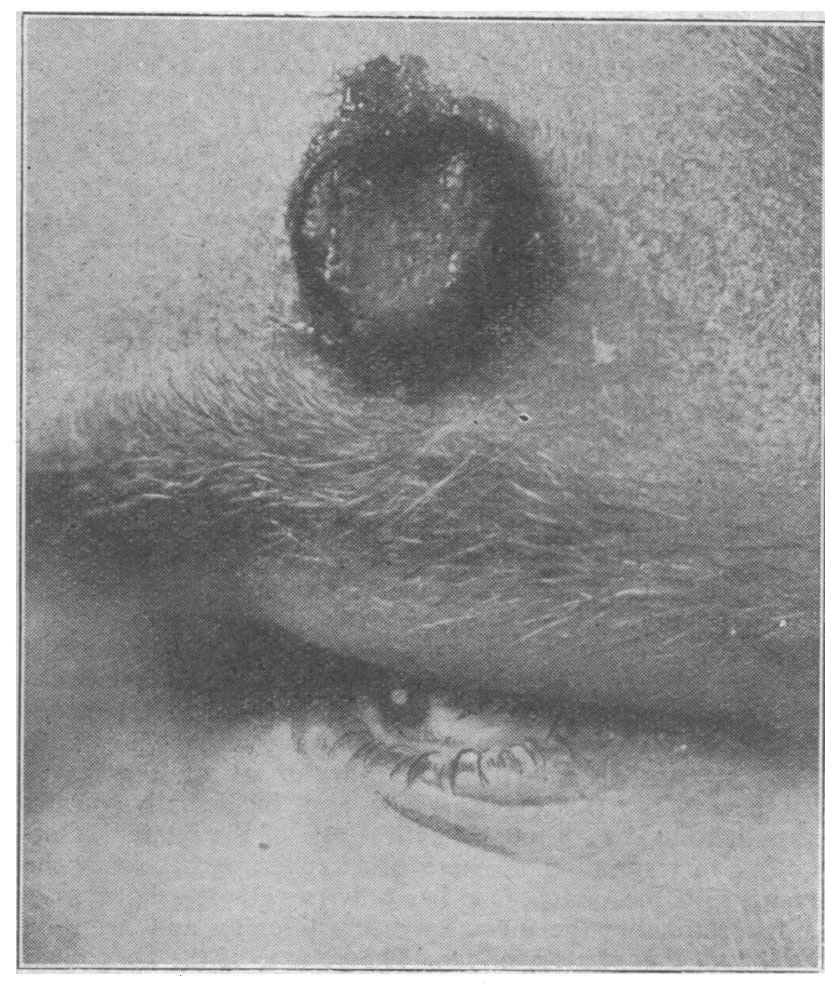

books of malignant pustule. These multiple lesions have been seen only where the patient has applied dressings prior to seeking advice.

The site of the lesion in the adult cases has generally been on the hands and forearm; predominantly on the hands and more usually on the dorsal aspect. The case described recently (G. M. Lloyd, A. Macelonald, and R. E. Glover, Lancet, 1951, 1, 720) illustrated a case where the brow of an adult was infected. Other facial lesions have always occurred in children, as reported by Dr. A. K. Rankin (British Medical Journal, 1950, 2, 1279). Once again two small girls with pet lambs have been seen with lesions on the lip and the temple respectively. The first post-war case was that of a farmer's schoolboy son who developed orf on his upper eyelid while bottle-feeding a lamb which had lost the ewe.

The condition resolves itself in five to eight weeks, as reported. Treatment with the earlier antibiotics has been unsatisfactory. Chloramphenicol and aureomycin have not been available in rural practice up to date. The sulphonamides have helped only to limit secondary infection. Very hot bathing, where assiduously applied after removal of scabs, has helped to shorten the course to about three weeks. Flavine in glycerin has been less useful. Zinc chloride
$(10 \%)$, as used by veterinary colleagues, has not had sufficient trial. If the eschar is repeatedly removed it appears beneficial, but it produces much soreness and the patient does not readily co-operate, though it would appear the most economical form of treatment.

Orf does not appear to penetrate the skin of the adult outdoor worker readily. There is usually a history of the worker having been recently employed in hedging, or retrieving the lamb from brambles and briars. No case of recurrent infection has been seen where the farm worker has in subsequent years handled infected sheep or lambs, so that immunity appears to be acquired.

The seasonal factor is apparently that of lamb-rearing. when stock are most frequently handled. Cases seen here have occurred between April and June and exceptionally as late as August.- I am, etc.,

$$
\text { Ross-on-Wye. }
$$

G. M. LLOYD.

\section{Pink Disease}

SIR,-I was very surprised to read in the British Medical Journal (April 28, p. 933) that treatment of pink disease with the use of salt and desoxycorticosterone had not met with success. I have had two cases of pink disease in my practice which were very successfully treated by giving 120 gr. $(7.2 \mathrm{~g}$.) salt daily and $3 \mathrm{mg}$. desoxycorticosterone acetate on alternate days, with a total of five injections. The response was almost immediate. The irritability and insomnia started to disappear and the appetite improved. About ten days later the redness of the hands and feet started to fade away. It is now over three weeks since treatment was started and the tachycardia has practically disappeared, along with most of the other symptoms and signs. - I am, etc.,

Manchester.

\section{H. FORMAN.}

\section{Kimmelstiel-Wilson Syndrome}

SIR,-Dr. Ian Gilliland's paper (April 28, p. 916) might have made clearer reading if he had defined his renal pathological groups more precisely. The use of the term arteriosclerosis without further definition or description is always confusing. We are told that in Group 1 (the KimmelstielWilson group) there is a pronounced degree of arteriosclerosis, and that this may be seen to affect both afferent and efferent arterioles. From these statements it must be implied that Dr. Gilliland includes arteriolosclerosis within the term arteriosclerosis, so that presumably Group 3, the arteriosclerotic group, includes kidneys showing arteriolosclerotic lesions and therefore overlaps Group 2.

It is generally considered that chronic hypertension is almost always associated with a significant degree of renal arteriolosclerosis. One is therefore surprised to find in Table IV that hypertension was present in only one of the three cases in the arteriolosclerotic group, in all three of the arteriosclerotic group, and in four of the "other diabetics" group, which by definition is free from renal vascular disease. This apparent lack of correlation between hypertension and renal pathology in the cases without Kimmelstiel-Wilson lesions also suggests that his various groups are far from clear cut.-I am, etc.,

$$
\text { London, S.E.5. G. F. M. HALL. }
$$

\section{Industrial Health Investigations}

SIR,-Your correspondents, Drs. R. S. F. Schilling (April 7, p. 759) and Alex. Mair (April 28, p. 950), comment upon industrial health investigation. They both refer to the work which requires physical examinations. I would point out that observations of less direct clinical interest, but not of minor importance, can be made from an examination of working methods. I think that the attitude to health in the lay mind has still a long way to go. You were kind enough to illustrate an arc-welder's shield which I designed (British Medical Journal, 1945, 1, 154). A foreman fitter- 